\title{
On the Economic Link Between Asset Prices and Real Activity
}

\author{
Juan Ignacio Peña and Rosa Rodríguez*
}

\begin{abstract}
This paper presents a model linking two financial markets (stocks and bonds) with real business cycle, in the framework of the Consumption Capital Asset Pricing Model with Generalized Isoelastic Preferences. Besides interest rate term spread, the model includes a new variable to forecast economic activity: stock market term spread. This is the slope of expected stock market returns. The empirical evidence documented in this paper suggests systematic relationships between business cycle's state and the shapes of two yield curves (interest rates and expected stock returns). Results are robust to changes in measures of economic growth, stock prices, interest rates and expectations generating mechanisms.
\end{abstract}

Keywords: stock market, interest rates, economic growth, term structure

\section{INTRODUCTION}

Economists have long understood that financial markets variables contain important information about the future of the economy. Financial market participants tend, by definition, to be forward-looking, and as a result prices of various securities embody expectations of future economic activity. This pricing behaviour implies that data from financial markets may reasonably be expected to help forecast the economy's growth rate. For instance, Stock and Watson (1989), Estrella and Hardouvelis (1991), Jeager (1991), Plosser and Rowenhorst (1994), Haubrich and Dombrosky (1996), Dotsey (1998) and Hamilton and Kim (2002) among others, point out that some current financial variables - in particular, term spreads, default spreads and stock returns are potentially useful in forecasting economic activity. However, this literature does not discuss explicit economic models to explain the empirical evidence.

\footnotetext{
* The authors are from Universidad Carlos III de Madrid. Partial financial support was provided by DGICYT grants PB98-0030, BEC2002-0279 and SEC2003-06457. Seminar participants at various universities and conferences provided useful comments. The authors thank the anonymous referee who provided astute comments that considerably improved the study. The usual disclaimer applies. (Paper received March 2005, revised version accepted August 2006. Online publication December 2006)
}

Address for correspondence: Rosa Rodríguez, Universidad Carlos III, C/Madrid 126, 28903 Getafe (Madrid), Spain. e-mail:rrlopez@emp.uc3m.es 
On the theoretical side, first-order conditions of a representative investor's lifetime problem may be used to study the joint behaviour of aggregate consumption and asset returns. If utility is time-additive isoelastic and consumption growth and asset returns are jointly lognormal, then a simple closed-form expression is obtained. It asserts that expected real consumption growth is linearly related to the expected real rate of return on a given asset.

Harvey (1988 and 1997) developed this idea and applied it to US and Canadian data in which asset returns are taken from US Treasury securities. He shows that term structure of interest rates provides better forecasts of economic activity than do simple time series models or stock market data used alone. In this paper, we generalize Harvey's (1988 and 1997) forecasting equation. We explicitly model the link between two financial markets (stocks and bonds) and the real business cycle. The theoretical framework is a version of the Consumption Capital Asset Pricing Model (CCAPM) with Epstein and Zin (1989) recursive preferences. The generalization implies that expected portfolio returns and expected consumption growth are linearly related. As a result, besides Harvey's interest rate spread, a new valuable forecasting variable appears: the market term spread, defined as the slope of expected stock market returns. Using Canadian and US data, we document empirically a systematic relation between stage of the business cycle and shapes of two yield curves: interest rates and expected returns in the stock market.

The CCAPM of Rubinstein (1976), Lucas (1978) and Breeden (1979) provides an important theoretical description of the intertemporal behaviour of asset returns. Despite its intuitive appeal, econometric tests by Grossman and Shiller (1981), Hansen and Singleton (1982), Mehra and Prescott (1985) and Cochrane (1992), among others, consistently reject the model. CCAPM's poor performance in empirical tests suggests that it may violate the assumptions underlying the model. For example, the expected utility preferences used to derive the model typically restrict the representative agent's risk aversion parameter such that it equals the reciprocal of agent's elasticity of intertemporal substitution parameter (Hall, 1988). This assumed inseparability of the desire to hedge risk from the desire to smooth consumption may itself lead to rejections of the consumption-based model in empirical tests. Epstein and Zin (1989) develop a class of nonexpected utility preferences that nest time, and state separable expected utility preferences as a special case, but separates agent's relative risk aversion and elasticity of intertemporal substitution parameters.

The characteristics of the Epstein-Zin specification of preferences are potentially appealing because the marginal rate of substitution of the consumption-based model depends on both consumption growth rate and returns of aggregate wealth. Therefore, it is possible that besides the information in the interest rate curve, stock market information may, jointly, be useful in explaining economic growth. In fact, we present empirical evidence supporting previous assertions using data from US and Canadian economies. The results suggest that both interest rates and the term structure of expected stock market returns contain information that can be used to forecast economic growth.

The paper is organized as follows. Section 2 presents the model that relates consumption growth and asset returns using recursive preferences. Section 3 describes the data and discusses some econometric issues. Section 4 computes expected stock market returns and reports empirical results. Some concluding remarks are offered in the final section. 


\section{THE MODEL}

Following Epstein and Zin (1989 and 1991) and Weil (1990), we assume that the representative investor has Kreps-Porteus Generalized Isoelastic Preferences (GIP) with constant elasticity of substitution $(1 / \rho)$ and constant coefficient of relative risk aversion $(\gamma)$. These preferences can be represented recursively as:

$$
V_{t}=\left[(1-\beta) C_{t}^{1-\rho}+\beta\left(E_{t} V_{t+1}\right)^{1 / \theta}\right]^{\theta},
$$

where $0<\beta<1$ is the subjective discount factor, $V_{t}$ is investor's utility at time $t, C_{t}$ denotes investor's consumption at time $t$, operator $E_{t}$ is the conditional expectation taken with respect to information available at time $t$, and parameter $\theta=(1-\gamma) /(1-\rho)$ measures departures from the investor's preferences from the time-additive isoelastic expected utility framework. Thus, when $\theta=1$, GIP preferences reduce to standard time-additive isoelastic expected utility representation.

Let $R i_{t+1}$ be (one plus) the random real return on asset $i$ from time $t$ to $t+1$, and let $m$ denote the claim on the portfolio of aggregate wealth. Epstein and Zin (1991) show that optimizing (1), subject to standard budget constraint yields the following set of Euler equations that characterize the solution to portfolio choice decision problem:

$$
E_{t}\left\{\beta^{\theta}\left(\frac{C_{t+1}}{C_{t}}\right)^{-\rho \theta} R m_{t+1}^{\theta-1} R i_{t+1}\right\}=1 \quad i=1, \ldots, N,
$$

and recursively we have the asset pricing equation:

$$
E_{t}\left\{\beta^{j \theta}\left(\frac{C_{t+j}}{C_{t}}\right)^{-\rho \theta} R m_{t+j}^{\theta-1} R i_{t+j}\right\}=1 \quad i=1, \ldots, N \quad j=1, \ldots, k .
$$

We can observe in (3) that stochastic discount factor for asset returns depends on both changes in aggregate consumption and changes in aggregate wealth portfolio ${ }^{1}$ return. We may use stock market returns as a proxy for the return on the portfolio of all invested wealth. This is a commonly used approach that allows us to develop a generalized version of Harvey's (1988 and 1997) model to study information in the term structure interest rate and market returns in order to explain economic growth. ${ }^{2}$ Therefore, $R m_{t+j}$ represents stock market real $j$-period return from time $t$ to $t+j$, and $R i_{t+j} \equiv R_{t+j}$ is real yield on a $j$-period risk-free bond.

If we assume homoskedasticity and joint lognormality of asset returns and consumption growth, this implies the following linear forecasting equation: ${ }^{3}$

$$
E_{t} \Delta c_{t: t+j}=\psi_{j}+\frac{(\theta-1)}{\theta \rho} E_{t} r m_{t+j}+\frac{1}{\theta \rho} E_{t} r_{t+j},
$$

1 Euler equations describing investor's optimal consumption portfolio plan may be written as $E_{t}\left\{M_{t+j} R_{i, t+j}\right\}=1$, where $M_{t+j}$ is the stochastic discount factor.

2 Stock market return is used as a proxy for the return on the portfolio of all invested wealth. One further extension for future research is to include other components of aggregate wealth portfolio like human capital.

3 Ferreira et al. (2003) show that there is no need of log-normality to linearize the Euler equation of a CCAPM with CRRA preferences. To obtain Harvey's model only stationary central moments are needed. 
where, $\psi_{j}$ depends on the model's parameters and on the conditional variance of the consumption-returns process, which we assume to be constant. ${ }^{4}$ The log consumption growth rate $\left(\ln C_{t+j}-\ln C_{t}\right)$ is $\Delta \mathrm{c}_{t: t+j}$ and lower cases in (4) denote logarithms $(r m=$ $\ln (R m))$. To study the information in the term structure of interest rates and market returns, equation (4) can be written as $j=1$ (short-term) and $j=k$ (long-term). Differentiating these equations give us a two-factor model to predict economic growth:

$$
\Delta c_{t+1: t+k}=a+\frac{(\theta-1)}{\theta \rho} E_{t}(\mathrm{MK})+\frac{1}{\theta \rho} E_{t}(\mathrm{YS})+u_{t+k} .
$$

Equation (5) says that expected consumption growth beginning one period ahead is linearly related to expected real stock market term spread $\left(\mathrm{MK}=r m_{t+k}-r m_{t+1}\right)$ and to real interest rate term spread (YS $=r_{t+k}-r_{t+1}$ ). We follow Harvey (1997) and assume that intercept $(a)$ captures the conditional variance of the consumption-return process. Furthermore, if we set $\gamma=\rho$ (i.e. $\theta=1$ ), model (5) reduces to Harvey's (1997) equation:

$$
\Delta c_{t+1: t+k}=a+\frac{1}{\gamma} E_{t}(\mathrm{YS})+u_{t+k}
$$

Given that the signs in the relationship between economic growth and explanatory variables (expected stock returns spread and interest rate spread) depends on the investors utility parameters $\rho$ and $\gamma$, it is useful to study their interactions. Note that $\theta=(1-\gamma) /(1-\rho)$ and therefore the slope coefficients in (5) may be expressed as $\mathrm{SMK} \equiv \frac{\rho-\gamma}{(1-\gamma) \rho}$ and SYS $\equiv \frac{1-\rho}{(1-\gamma) \rho}$ for stock market term spread and interest rate spread respectively.

\begin{tabular}{|c|c|c|c|c|}
\hline & \multicolumn{2}{|c|}{$\rho>1$} & \multicolumn{2}{|c|}{$\rho<1$} \\
\hline$\gamma>1$ & $\begin{array}{c}\rho>\gamma \\
\text { SYS }>0 ; \text { SMK }<0\end{array}$ & $\begin{array}{c}\rho<\gamma \\
\text { SYS }>0 ; \text { SMK }>0\end{array}$ & \multicolumn{2}{|c|}{$\begin{array}{c}\rho<\gamma \\
\text { SYS }<0 ; \text { SMK }>0\end{array}$} \\
\hline$\gamma<1$ & \multicolumn{2}{|c|}{$\begin{array}{c}\rho>\gamma \\
\text { SYS }<0 ; \text { SMK }>0\end{array}$} & $\begin{array}{c}\rho>\gamma \\
\text { SYS }>0 ; \text { SMK }>0\end{array}$ & $\begin{array}{c}\rho<\gamma \\
\text { SYS }>0 ; \text { SMK }>0\end{array}$ \\
\hline
\end{tabular}

The following presents possible combinations:

Published empirical evidence for both parameters offers a wide range of values. Estimates for the elasticity of substitution $(1 / \rho)$ based on macroeconomic data range from near zero (say 0.1) by Hall (1988) and Campbell and Mankiw (1989) to near unity by Beaudry and van Wincoop (1995). Epstein and Zin (1991) provide estimates spanning the range 0.05 to 1 . Thus, $\rho$ would be in the range 1-20. Rodríguez et al. (2002), matching the predictability and volatility of stock returns, estimate $\rho$ to range from 4.1 to 5.1 for USA and from 2.9 to 4.8 for Canada. Matching correlations between

4 This parameter, $\psi_{j}=\frac{j}{\rho} \ln \beta+\frac{1}{2} v_{t, j}$, is not constant in all periods, because it depends on conditional variance $\left(v_{t, j}\right)$ in equation (4). Furthermore it may be possible that consumption growth volatility and asset return volatility are related to future real activity. We thank the anonymous referee who pointed out this interesting area for future research. 
international stock returns increases its value to near 12 for both countries (Restoy and Rodríguez, 2006).

Estimates of the coefficient of relative risk aversion, $\gamma$, show even more dispersion. Epstein and Zin (1991) find values around unity that are consistent with the logarithmic utility function, whereas papers about the equity premium puzzle employ values as high as 18 (Obstfeld, 1994) or even 30 (Kandel and Stambaugh, 1991). However, Constantinides, Donaldson and Mehra (2002) suggest that $\gamma$ lies most plausibly in the range from 2 to 5 , a suggestion that appears to be increasingly accepted. To summarize, the empirical evidence suggests that $\rho>1$ and $\gamma>1$, which corresponds to the first quadrant in the previous table. In this case, the interest rate term spread coefficient is always positive, but the stock market term spread coefficient would be negative if $\rho>$ $\gamma$ and positive when $\rho<\gamma$. For instance, considering reasonable values such as $\rho=10$ and $\gamma=3$, would imply SYS $>0$ and SMK $<0$.

\section{DATA AND ECONOMETRIC ISSUES}

\section{(i) Econometric Issues}

The two-factor model (5) links expected real spreads to real consumption growth. Because real spreads are not observable, Harvey (1989 and 1997) proposes the use of yield spreads between nominal yields of zero-coupon bonds. ${ }^{5}$ Further support for Harvey's approach can be found in Ferreira et al. (2003). They show that for theoretical CCAPM and its empirical version to be consistent, expected real interest must be linearly related to nominal yield spreads. They find strong support for links between economic agent expectations and yield spreads. In fact, nominal yield spreads are found to be good predictors of expected real interest rates.

On the other hand, Stock and Watson (2003) state that the reason why interest rate term spread predicts output lies in its role as indicator of effective monetary policy. To clarify how this monetary effect fits into the real Euler equation that forms the theoretical foundation of this paper, we separate real from nominal interest rate term structure effects. We compute expected real interest rates by subtracting out-of-sample forecasts of inflation from nominal risk-free interest rates. Therefore, interest rate term spread is computed as the difference between real annualized long-term and short-term yields to maturity of risk-free bonds. Similarly, stock market term spread is generated as the difference between real annualized long-term and short-term expected stock market returns.

To test econometric model (5) we require the expectation in $t$ of two spreads. The problem is that while interest rate spread is readily available (using procedures similar to the one described above), expected stock market spread is not. So, in time $t$ we know the expected yield for a safe investment maturing in $t+j$ years $\left(E_{t}(\mathrm{YS})=\mathrm{YS}_{t}\right)$, but we can forecast expected stock market prices only $j$ years ahead.

Thus, before computing expected stock market yield curve, we must provide a generating mechanism for expected stock market returns, $\left(E_{t}\left(r m_{t+j}\right)\right)$. To solve this problem, we use the results from the empirical literature on financial markets

5 He argues that under several specifications for inflation process, nominal yield spread approximates expected real yield spread. Thus, if inflation follows a first-order integrated moving-average process or a firstorder autoregressive model with an autoregressive parameter close to unity, annualized inflation forecasts are similar, irrespective of the forecasting horizons. 
documenting predictability of aggregate stock returns or the equity premium from past information, including lagged returns (Fama and French, 1988a; and Poterba and Summers, 1988), the dividend-price ratio and dividend yield (Campbell and Shiller, 1988; Fama and French, 1988b; Hodrick, 1992; Lewellen, 2004; and Menzly, Santos and Veronesi, 2004; among others), short-term interest rates (Campbell, 1987; and Hodrick, 1992), yield spreads between long-term and short-term interest rates and between low and high quality bond yields (Campbell, 1987; Fama and French, 1989; and Keim and Stambaugh, 1986). Lettau and Ludvigson (2001) have shown that the proxy for the log of consumption-to-wealth ratio helps to forecast quarterly real asset and portfolio returns. Following these suggestions from the literature, we forecast the stock market returns through six variables: dividend yield, short term interest rates, exchange rates, default premium, the differential between domestic and foreign short term interest rates, and a proxy of the log of consumption-to-wealth ratio.

The asset-pricing model (2) links asset returns to the ratio of the marginal utility of consumption today to the marginal utility of consumption tomorrow. Unfortunately, true consumption is never observed. Researchers must use proxies for the consumption variable. Many tests of the asset-pricing model use the personal consumption of nondurables and services. Given the difficulties in measuring aggregate consumption, we start using growth in real Gross Domestic Product (GDP) in this paper rather than measured consumption ${ }^{6}$ as the left-hand variable in the estimation of equation (5). To check the robustness of our results, we also report the performance of our factor model in forecasting consumption growth using aggregate consumption data instead of GDP data.

Finally, the use of overlapping observations in equation (5) induces a fourth-order moving average process in error terms. The ordinary least squares (OLS) parameter estimates would be inefficient and hypothesis tests would be biased. In order to account for this concern, we employ the heteroskedasticity and autocorrelation-consistent (HAC) standard errors of Newey and West (1987) to obtain asymptotically valid hypothesis tests.

\section{(ii) Data Sources}

Quarterly data for the period 1969:4 to 2003:3 for two OECD countries - Canada and the United States ${ }^{7}$ - are employed in this paper.

Aggregate stock returns and dividend yields for each country have been obtained from Morgan Stanley Capital International (MSCI). Output measure is the annual growth rate of real Gross Domestic Product, seasonally adjusted (OECD 42100372 and 44100322 series for USA and Canada respectively $)^{8}$. Exchange rates are measured by US\$/CA\$ exchange rate monthly average (OECD 447003D). The proxy for log of consumption to wealth ratio (cay) is obtained from the homepage of Professor Ludvigson (http://www.econ.nyu.edu/user/ludvigsons/). The default spread is

6 Harvey (1989) explored a similar forecasting model using the growth rate in real GNP as a proxy for unobservable consumption.

7 These economies are selected because the theoretical framework used in this paper implies a general equilibrium perspective, under segmented capital markets, where output is explained primarily by domestic factors. Thus, it may be argued that US and Canadian economies are not far from the model's assumptions. 8 We denote $\log$ real GDP growth from $t$ to $t+h$, expressed at an annual frequency as $\frac{400}{h}\left(\ln y_{t+h}-\ln y_{t}\right)$, where factor 400 standardizes units from quarterly growth rate to annual (\%) growth rates. 
defined as the difference between long-term BAA Moody's corporate bonds and long-term US Treasury bonds. Data are available at the Federal Reserve Bank of St. Louis homepage.

For both explanatory variables in equation (5) we consider two term spreads (3year, 90-day and 5-year, 90-day term spreads) to compare the maturity that best reflects the model's specification. Thus, for Canada, the first bond yield spread is Selected Government of Canada Benchmark three-year bond yield (Bank of Canada - v122539) minus three-month T-bills auctions (average yields) (B14007 - Bank of Canada). The second spread is Selected Government of Canada Benchmark five-year bond yield (Bank of Canada - B14010) minus three-month T-bills average yields. The Canada Benchmarks bond yields are available from 1982 for the three-year case and from 1980 for the five year case. ${ }^{9}$

The US bond yield term spreads include a three-year (or five-year) Treasury constant maturity rate average of business days (Federal Reserve Board of Governors H.15), minus the three-month T-bills money market (OECD 42M3A1).

For consumption data, we use time series data of privately available final consumption expenditures, in chained constant prices, seasonally adjusted (USA110101 and CAN110121 OECD).

To model expected inflation, the variable of interest is rate of change in implicit price deflator for GDP, seasonally adjusted (441021 and 421021 OECD) from 1963:3 to $2004: 4$.

It must be noted that given the specific features of the new factor, some data points are lost in the estimate of market term spread. For example, for five-year market spreads, 20 data points are lost when computing returns from the local index and another 20 data points when computing expectations. This is the reason we use 3-year, 90-day and 5-year, 90-day term spreads rather than 3-year, 90-day and 10-year, 90-day term spreads as used by Harvey (1997). The sample used in the econometric estimation of equation (5) covers the period 1981:1 to 2003:3.

\section{EMPIRICAL RESULTS}

\section{(i) Estimating Expected Inflation}

To compute expected real interest rates, we need a model of expected inflation. Inflation forecasts from $t$ to $t+1$ for all the models are based on information available at time $t$. The parameters of each model are re-estimated at every point in the series and $j$-step forecasts are computed.

We examined different univariate time-series models of quarterly inflation processes and selected the one that minimizes Akaike's AIC criteria. The processes appear to follow an IMA(1,1) for both the United States and Canada over the period 1963:3 to 2004:4. Full-sample estimates for inflation rate $\left(\pi_{t}\right)$ are as follows. For the USA, GDP deflator data, the estimated model is:

$$
\pi_{t}=0.00001+\pi_{t-1}+e_{t}-0.537 e_{t-1} R^{2}=24 \%,
$$

$$
(0.0001)
$$

9 We repeated the analysis computing Canada term spreads using 1-to-3-year and 1-to-5-year bonds, rather than a constant maturity 3- or 5-year bond (available from 1949 and 1951). Results do not change in any significant way. 
and standard errors appear in parenthesis. For Canadian GDP deflator data, the estimated model is:

$$
\pi_{t}=0.00001+\pi_{t-1}+e_{t}-0.632 e_{t-1} \quad R^{2}=25 \% .
$$

The IMA $(1,1)$ is estimated first, over an initial period of ten years (40 observations). Fitted values provide inflation forecasts in this period. After this initial estimation period, the model is reestimated at each point in the time series and $j$-step ahead forecasts are obtained. Inflation forecasts are then subtracted from nominal interest rates in order to calculate expected real rates.

\section{(ii) Computing Expected Stock Market Returns}

Expected real stock market term spread from (5) is:

$$
E_{t}(\mathrm{MK})=E_{t}\left(r m_{t+j}\right)-E_{t}\left(r m_{t+1}\right) \quad j=12,20,
$$

where $r m_{t+j}$ represents annualized stock market real returns in $t+j, j=1$ represents a short term (one quarter), and $j=12,20$ a long term (three and five years, respectively). Nominal expected stock returns are fitted values of the model:

$$
\operatorname{er}_{t+j}=\alpha+\beta X_{t}+\varepsilon_{t+j} \quad j=1,12,20
$$

where $e r_{t+j}$ represents nominal excess stock market returns and $X_{t}$ is a vector containing, for the US case, the following lagged variables: the natural logarithm of the annual dividend yield, the domestic short-term interest rate measured in deviations from the one-year moving average, a proxy for log consumption-wealth ratio, the default premium, and the differential of Canadian the short-term interest rate from US short-term interest rate. The explanatory variables for the Canada case are: the natural logarithm of the annual dividend yield, the domestic short-term interest rate measured in deviations from the one-year moving average, the exchange rate US $\$ / C A \$$ and the differential of the Canadian short-term interest rate from US short-term interest rate.

Some possible caveats are worth mentioning. If the estimation of stock market spreads uses the full sample a potential look-ahead, bias may be generated. To address this concern, we perform out-of-sample forecasts where parameters are estimated every period, using only data available at the time of making forecasts. Thus we run rolling regressions to remove the look-ahead bias. For each regression, a vector of estimated parameters is obtained, which will be used to predict the endogenous variable for the next period and to compute the rolling residues. Starting at 1969:4, an initial window of 45 observations is used; we then add the remaining observations one by one until the end of the sample.

Given that we need out-of-sample forecasts of the returns, it is worth mentioning an important issue noted in recent literature. Butler, Gryllon and Weston (2004) and Goyal and Welch (2004) indicate that many variables correlated in-sample with stock returns and used to forecast aggregate returns present weak performance predicting out-of-sample. These variables seem to be unable to beat a simple forecast based in historical average stock returns. Campbell and Thompson (2005) show that 
model-based forecasts of returns may beat the historical average when some restrictions are imposed on the estimation process. They adopt the perspective of an investor who will not mechanically employ the linear regression results without imposing some restrictions. For example, the investor does not give credit to forecasts of negative risk premium. When the model forecasts a negative risk premium, the investor uses a pre-specified value instead. Following the suggestions of Campbell and Thompson (2005), we set that forecast at zero when the model forecasts a negative risk premium - this in the spirit of Litterman (1986), who imposed Bayesian prior information on parameters in order to deal with similar problems encountered when forecasting some macroeconomic series. The forecast restriction we impose here can be interpreted as a uniform prior in a restricted part (only non-negative forecasts) of the parameter space. Furthermore, as Campbell and Shiller (2001) pointed out, when independent variables are far from their historically observed average range, it may not be safe to take linear regression results at face value. In order to deal with those situations, we replace independent variable data above or below two standard deviations from the historical average with the maximum (mean $+2 *$ s.d.) or minimum (mean $-2 *$ s.d.) of the interval so defined.

Results of rolling regressions (available on request from the authors) suggest that explanatory variables are jointly significant in Canada and the USA, with similar forecasting power. With quarterly returns, the model explains, on average, $14 \%$ of the variability of returns for Canada and $15 \%$ for the USA. When we use 3-year returns, explanatory power of right hand side variables is about $50 \%$ for Canada, and $56 \%$ for the USA. For 5-year returns, explanatory power ranges from $61 \%$ for Canada to $74 \%$ for the USA. In all cases we reject the null hypothesis that all slope coefficients (excluding the intercept) are zero. As usual, larger $R^{2}$ statistics are obtained at longer horizons.

Expected excess nominal stock market returns and expected real stock market returns are shown in Figures 1, 2, 3 and 4. Monthly percentages are used to allow us to compare our ex-ante equity premium results with those in Campbell and Thomson (2005). If we compare Figure 1 with Figure 1 (Panel A) in Campbell and Thomson (2005), for instance, we can observe that both excess returns are in the same order of magnitude (from $0 \%$ to $1.8 \%$, approximately).

We can also observe that short-term expected returns are sometimes above and sometimes below long-term, suggesting that stock market spreads can be either positive or negative. Furthermore, the volatility of long-term expected returns is lower than the volatility of short-term expected returns. An additional point mentioned in Campbell et al. (2001) is the effect of the October 1987 crash that caused an enormous spike in market volatility. Following the suggestions in Campbell et al. (2001), we replaced the observation in October 1987 with the second largest observation in the data set. This somewhat naive procedure decreases the influence of the crash, but leaves it as an important event in the sample.

As a further illustration, Figure 5 shows ex-ante equity premiums computed over 5 -year periods. Their average value $(7.6 \%$ per annum) looks reasonable in comparison with values reported in the literature. ${ }^{10}$

10 The equity premium literature is vast and growing. For recent reviews see Derrig and Orr (2003) and Mehra and Prescott (2003). 
Figure 1

US Expected Excess Returns

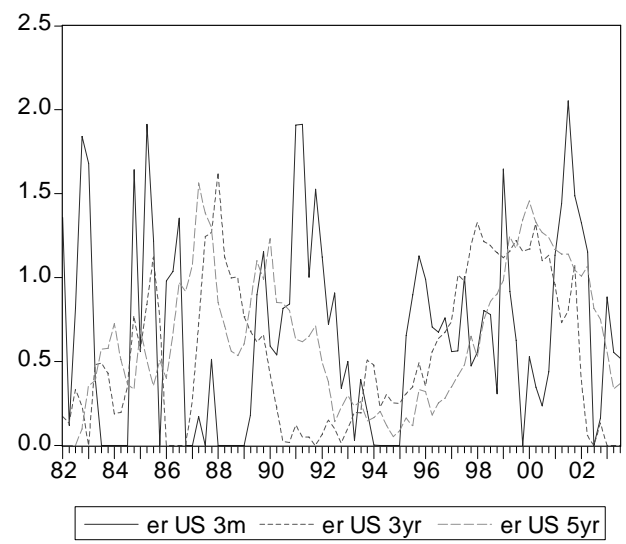

Notes:

This figure presents expected excess nominal returns where, in case of negative risk premium forecast, expected return is set equal to zero. Units are monthly percentages.

Figure 2

CA Expected Excess Returns

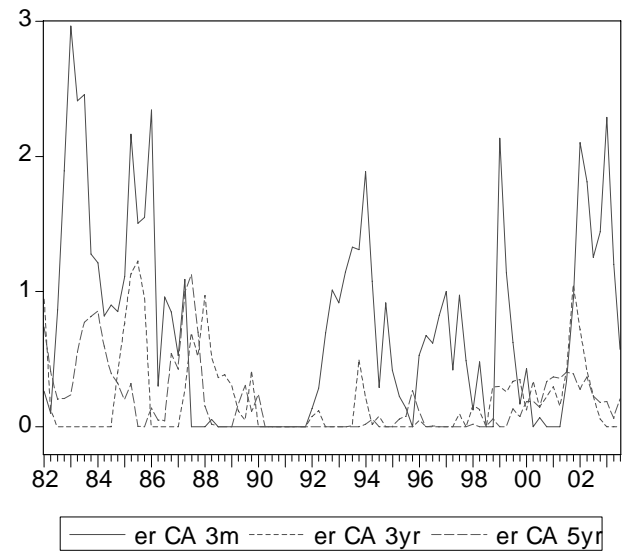

Notes:

This figure presents expected excess nominal returns, where, in the case of negative risk premium forecast, expected return is set equal to zero. Units are monthly percentages.

(iii) Estimation Results for the Two Factor Model

Preliminary statistical information on the variables to be included in the estimation of the two-factor model (5) can be found in Table 1. The table reports summary statistics 
Figure 3

\section{US Expected Returns}

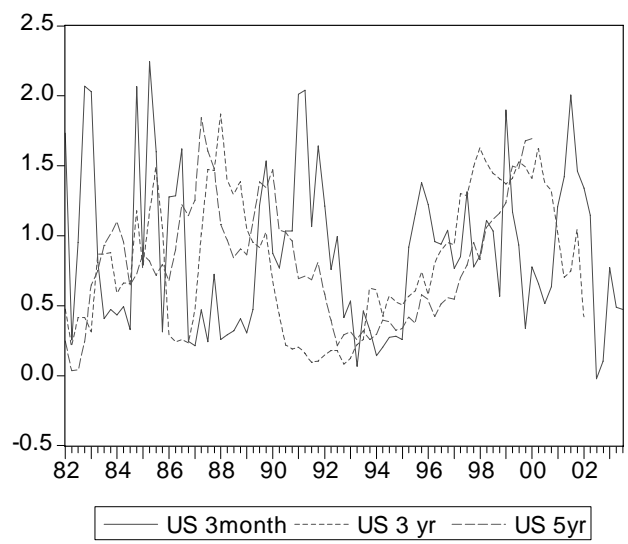

Note:

This figure presents expected real stock market returns, in monthly percentages.

Figure 4

CA Expected Returns

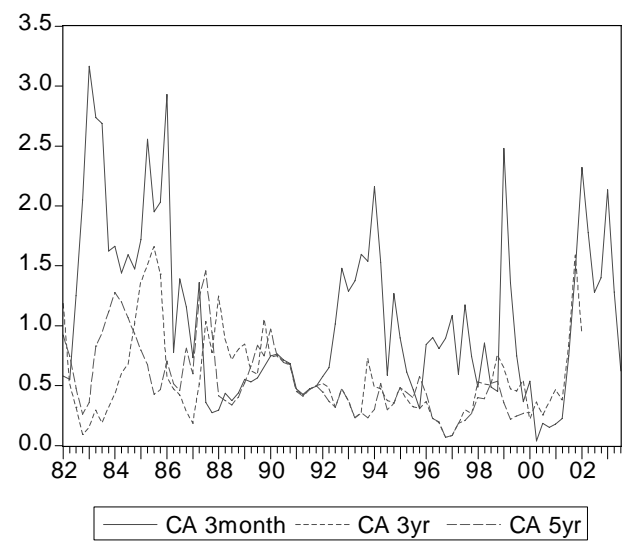

Note:

This figure presents expected real stock market returns, in monthly percentages.

of real consumption growth and real GDP growth, real interest rate term spreads (3-year and 5-year) and estimated real stock market term spread (3-year and 5-year) computed by the methods explained in the previous section.

As we can observe in Table 1, average economic growth and average interest rate term spreads in our sample are positive, whereas average expected stock market spreads 


\section{Figure 5}

Average Ex-ante US Equity Risk Premium Over 5-year periods

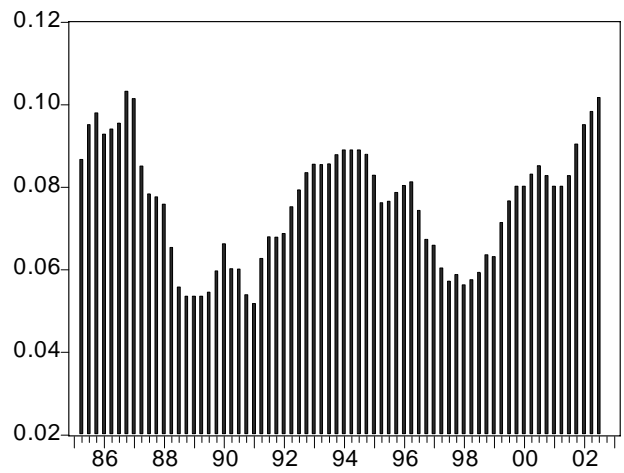

Notes:

This figure presents expected excess nominal returns averaged over 5-year periods. Units are annual percentages.

are negative. The second panel of Table 1 presents correlations between factors to be included in our model. Spreads are lagged five periods to match equation (5). For both countries we can observe a positive correlation between interest rate spreads and economic growth measured either through consumption or output. Stock market term spreads give different results. As for the Canadian data, correlations between stock market spreads and economic growth are negative for both the 3-year and 5-year term spread. The same negative correlation is observed in US data (GDP), but not with consumption data, for which the correlation is positive (near zero) using 3-year stock market term spread. Furthermore, all US stock market-consumption correlations are lower than those reported for the Canadian data.

Note that correlations between bond and stock market spreads are not negligible for Canada, given that approximate standard error is 0.106 . Correlations are -0.29 for the spreads of both terms. To check possible multicollinearity problems, we computed the condition number. Belsley et al. (1980) suggest that if the condition number is above 20 , multicollinearity is a serious concern. In our data the condition number is lower but, given the high correlations between some of the explanatory variables, we decided to orthogonalize regressors to avoid potential problems of multicollinearity. Thus, market term spread is regressed on an intercept and interest rate term spread. The residuals of this regression are the new variable ( $\hat{\mathrm{MK}})$ used rather than MK as a stock market factor.

To provide a visual representation of the time evolution of the variables in the twofactor model, GDP growth, real interest rate term spread, and real expected stock market term spreads (3-year and 5-year) are graphed in Figures 6 to 9. Term spreads are lagged five periods to match the implied linearity in equation (5). There are two main facts. First, interest rate spreads and GDP growth move closer together in all cases. Second, there is a positive correlation between GDP growth and lagged interest rate spread, as mentioned in Table 1 and noted by Harvey (1997), and also we may notice negative correlation between GDP growth and lagged stock market spread. Shaded 
Table 1

Summary Statistics of the Regressors to be Included in the Estimation of the Two-Factor Model

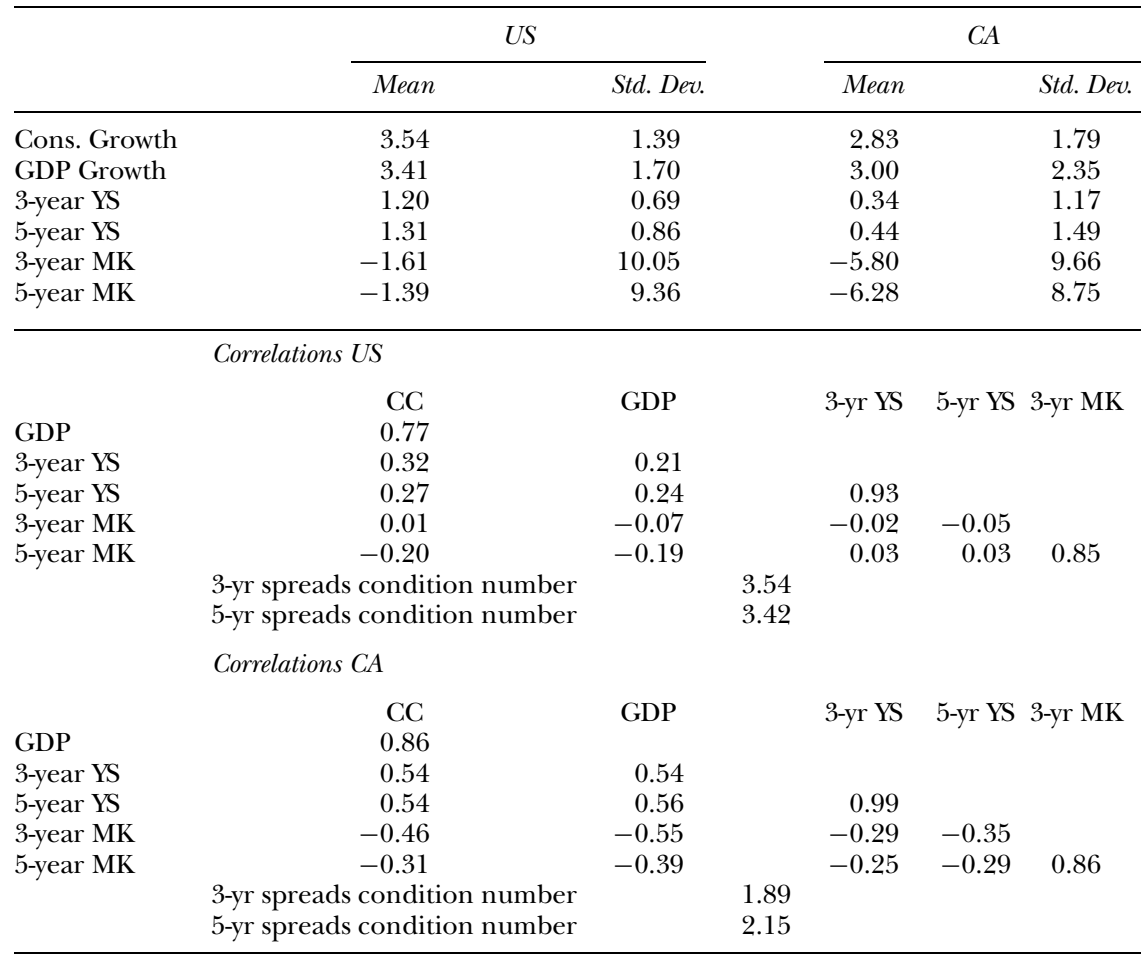

Notes:

This table reports means, standard deviations and cross correlations of real GDP growth, interest rate yield spreads (3-year and 5-year) YS, and estimated stock market term spreads (3-year and 5-year) MK. Spreads are lagged five periods to match equation (5). Sample period is 1981:1-2003:3.

regions are NBER recessions for the USA; business cycle chronologies for Canada are from Bodman and Crosby (2000).

The estimation of the two-factor model (5) and one-factor model of Harvey (1997), both with term spreads using different horizons, is presented in Table 2. Before analyzing the results, an additional econometric problem - the generated regressors' bias - is worthy of mention. We estimated expected stock market returns in a first-stage procedure, from the multivariate fundamental regressions, equation (8). After that, we used those predicted (estimated and orthogonalized) values of the stock market spread as the regressors in the second regression model (5). If one is interested in the estimator's consistency, replacing the regressor in (5) with predicted values from multivariate regressions (8) creates no problem. However, standard errors and test statistics obtained in the second step are generally invalid because they do not account for the sampling variation in estimated coefficients from the first step. Because they 
Figure 6

US GDP and 3-yr Spreads

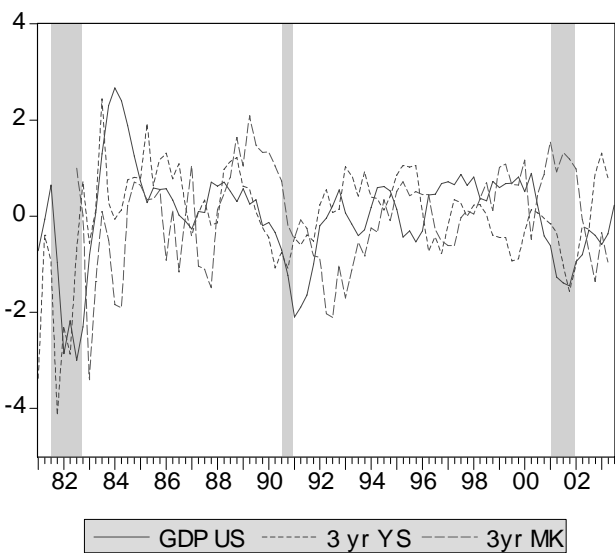

Notes:

This figure presents annual growth rate of GDP, seasonally adjusted; expected interest yield spread (3-yr,90 days); and expected stock market yield spread computed through fundamentals. Spreads are lagged five periods to match equation (5) with $k=5$. Data have been normalized. Shaded regions are NBER recessions.

Figure 7

US GDP and 5-yr Spreads

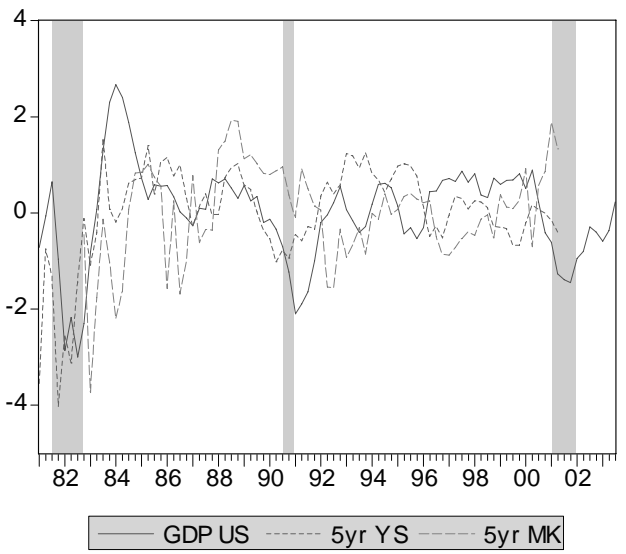

Notes:

This figure presents annual growth rate of GDP, seasonally adjusted; expected interest yield spread (5-yr, 90 days); and expected stock market yield spread computed through fundamentals. Spreads are lagged five periods to match equation (5) with $k=5$. Data have been normalized. Shaded regions are NBER recessions. 
Figure 8

\section{CA GDP and 3-yr Spreads}

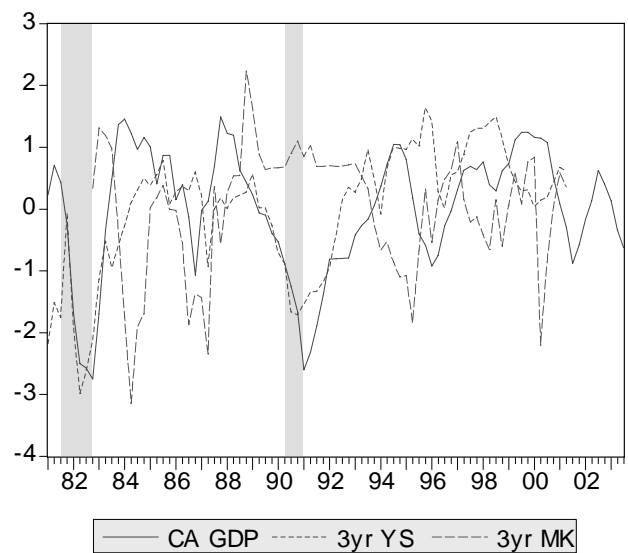

Notes:

This figure presents annual growth rate of GDP, seasonally adjusted; expected interest yield spread (3-yr, 90 days); and expected stock market yield spread computed through fundamentals. Spreads are lagged five periods to match equation (5) with $k=5$. Data have been normalized. Shaded regions are Canada's recessions.

\section{Figure 9}

\section{CA GDP and 5-yr Spreads}

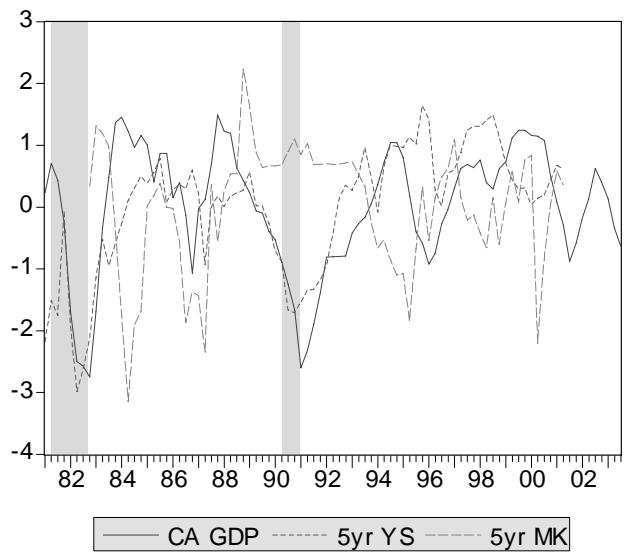

Notes:

This figure presents annual growth rate of GDP, seasonally adjusted; expected interest yield spread (5-yr, 90 days); and expected stock market yield spread computed through fundamentals. Spreads are lagged five periods to match equation (5) with $k=5$. Data have been normalized. Shaded regions are Canada's recessions. 
are also obtained using the same sample data, uncertainty about the estimates should be accounted for in the second step. Nevertheless, there is one important case in which this sampling variation is not as damaging, at least asymptotically: when residuals in equation (5), the second step, are orthogonal to regressors used in both the second and the first step. In that case, standard errors in the second step are not invalid. This condition holds in our model as well as in some other generated regressor contexts. ${ }^{11}$

The results for the one-factor model indicate that coefficients on interest rate term spread are positive and highly significant for Canadian GDP data at all horizons, and for both the 3-year and 5-year spread. Estimated coefficients range from 0.61 to 1.10 for the 3-year spread and from 0.53 to 0.88 for the 5 -year spread. Estimated values decrease with the forecasting horizon. Adjusted $R^{2}$ varies from $25 \%$ to $30 \%$ for the 3 -year spread and from $27 \%$ to $30 \%$ for the 5 -year spread. Basically, there are few variations in the Canadian data as it relates to the term. ${ }^{12}$

The predictive power of yield curve for the US GDP data varies with maturity. Thus, the 3-year term spread significantly predicts GDP growth at all horizons, whereas the 5 -year term spread does not significantly predict GDP. For 3-year yield spreads, the coefficient is also positive and significant - ranging from 0.49 to 0.75 - and $R^{2}$ varies from $8 \%$ to $10 \%$.

Once the expected stock market term spread is forecasted through fundamental variables and the inflation process computed, the estimation of the two-factor model shows that coefficients of interest rate term spread remain statistically significant in the same cases as before, at conventional levels. Coefficients of stock market term spread are negative and statistically significant for Canadian data in all cases, and the addition of the stock market term spread increases explanatory power, as measured by $R^{2}$. For the one-year horizon $(k=5)$, for example, explanatory power is $45 \%$ (30\% in the one-factor model) for the 3-year model and 35\% (30\% in the one-factor model) for the 5-year model. The increase is similar for the 2-year horizon: $43 \%$ instead of $30 \%$ in the one-factor model and $35 \%$ instead of $28 \%$, and for the 3 -year horizon $37 \%$ instead of $25 \%$ and $35 \%$ instead of $27 \%$.

Results differ for the US data: the stock market term spread is significant only four times out of six for 2-year and 3-year horizons with both stock market term spreads. In these cases the coefficient's signs are negative and explanatory power also increases with respect to the one-factor model.

Table 2 presents a column with a test for the $\theta$ parameter. ${ }^{13}$ When this parameter is equal to one, the two-factor model reduces to a one-factor model. Also it indicates how investor preferences differ from the standard isoelastic preferences. We may observe that when the stock market term spread factor is statistically significant, as in the Canadian data, the $p$-value indicates that we may reject the null hypothesis of $\theta=$ 1 at reasonably significant levels. For the US data, the null hypothesis is rejected three times at the $5 \%$ level. Thus, we may interpret the empirical results reported in Table 2 as being favourable to CCAPM, with GIP preferences for the Canadian economy. Results are not as clear for the US economy.

11 See Chapter 6 of Wooldridge (2002) for a complete explanation of the zero conditional mean condition. 12 Harvey (1997) found that the 3-year maturity was more appropriate than the 10-year maturity for the estimation of the model.

13 It is easy to see that we can recover the value of $\theta$ from $\alpha_{2}$ and $\alpha_{3}\left(\theta=1+\left(\alpha_{3} / \alpha_{2}\right)\right)$. 


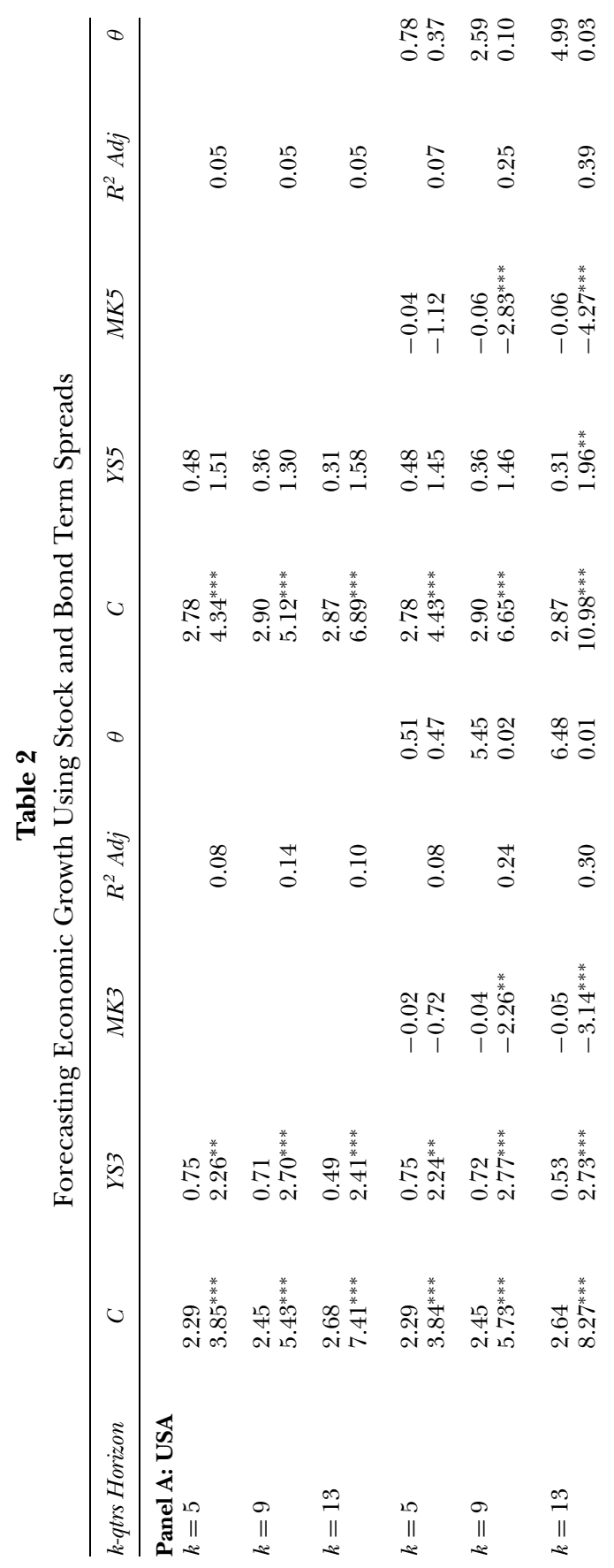




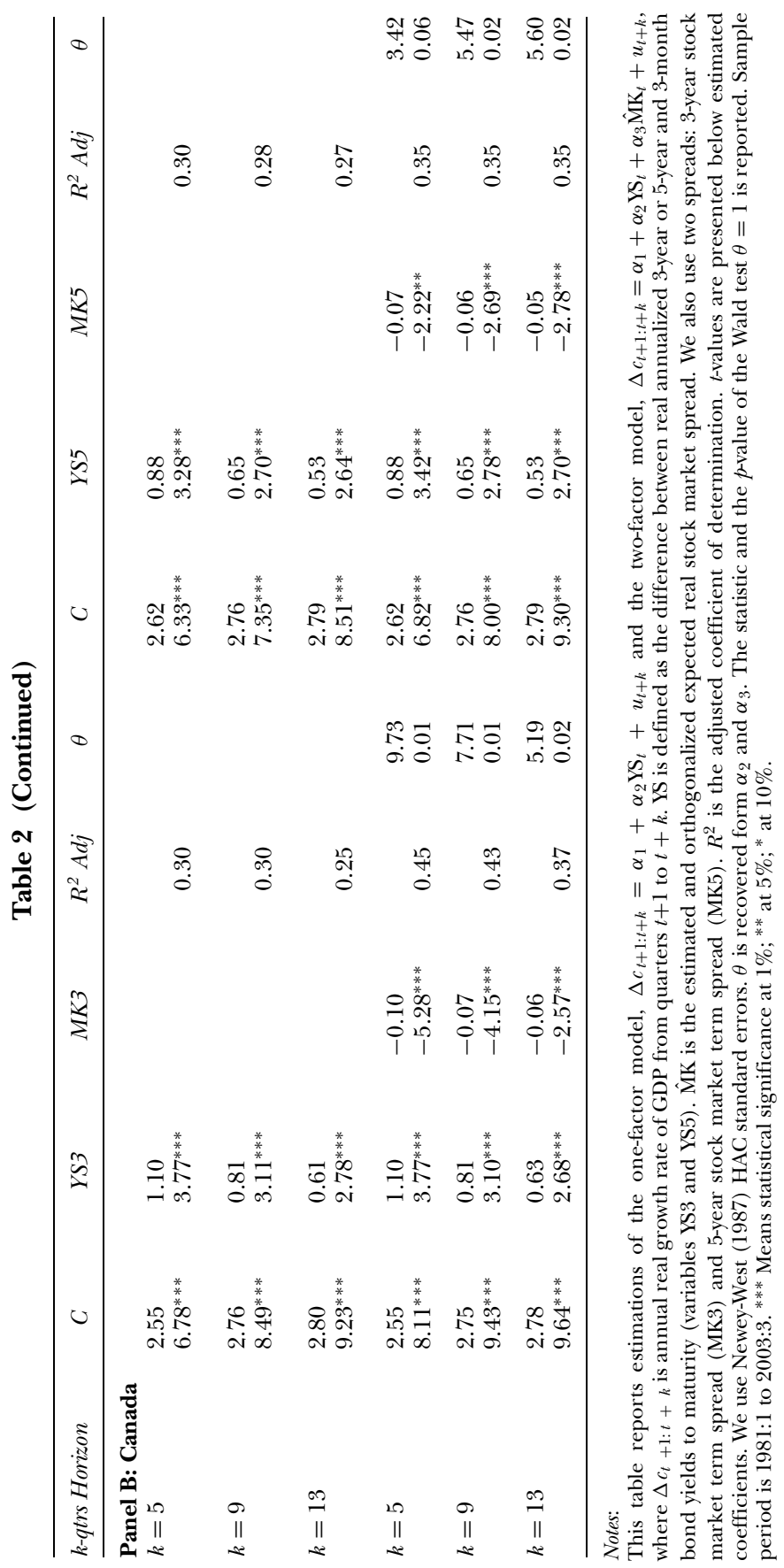


As a further robustness check, we report the performance of the models in forecasting consumption growth, using consumption data rather than GDP. Results are presented in Table 3 .

Regarding consumption data results, we find two main facts. First, the interest rate variable retains the same behaviour as with the GDP for both countries. Canadian interest rate spreads are significant at reasonable levels in all cases, but US interest rate spreads are significant only twice with the 3-year term. Second, estimation of the two-factor model shows estimated coefficients for the stock market term spread to be negative and significant according to $t$-statistics for Canada 5 out of 6 times, but only in 3 out of 6 for USA. ${ }^{14}$ This is not a surprising finding, given the low correlations shown in Table 1 between consumption and stock market term spread (0.01 for the 3-year spread and -0.07 for the 5 -year spread).

It seems reasonable to look for reasons for the model's apparent failure with the US data. Given the different sign in correlation between US stock market factor and the proxy of economic growth using consumption or GDP, we graph consumption growth and GDP growth series for the US data in Figure 10. We can observe that consumption growth is sometimes above and sometimes below GDP growth, but it is systematically above GDP growth during the technology bubble and in its aftermath. ${ }^{15}$ These facts may suggest that, in this period of approximately five years, the growth of GDP was basically due to heavy borrowing rather than strong investment and productivity growth. Therefore, this period might cause non-trivial structural changes in our sample. Panel A of Table 4 reports some correlations. The table shows that correlations

Figure 10

US GDP and Consumption Growth

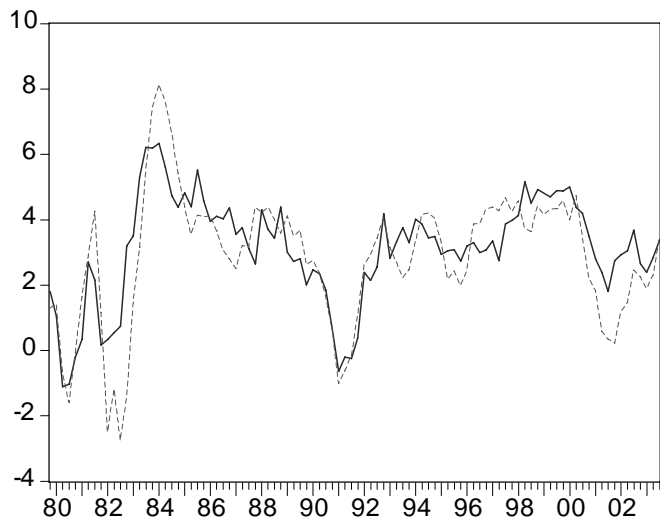

Consumption Growth----. GDP Growth

14 The same results are found if we use different measures of aggregate consumption: the consumption expenditures in nondurable goods and services instead of private final consumption expenditures. Detailed results are available on request from the authors.

15 Brunnermeier and Nagel (2004) define the highest peak in the internet bubble as being from January 1998 to December 2000. 


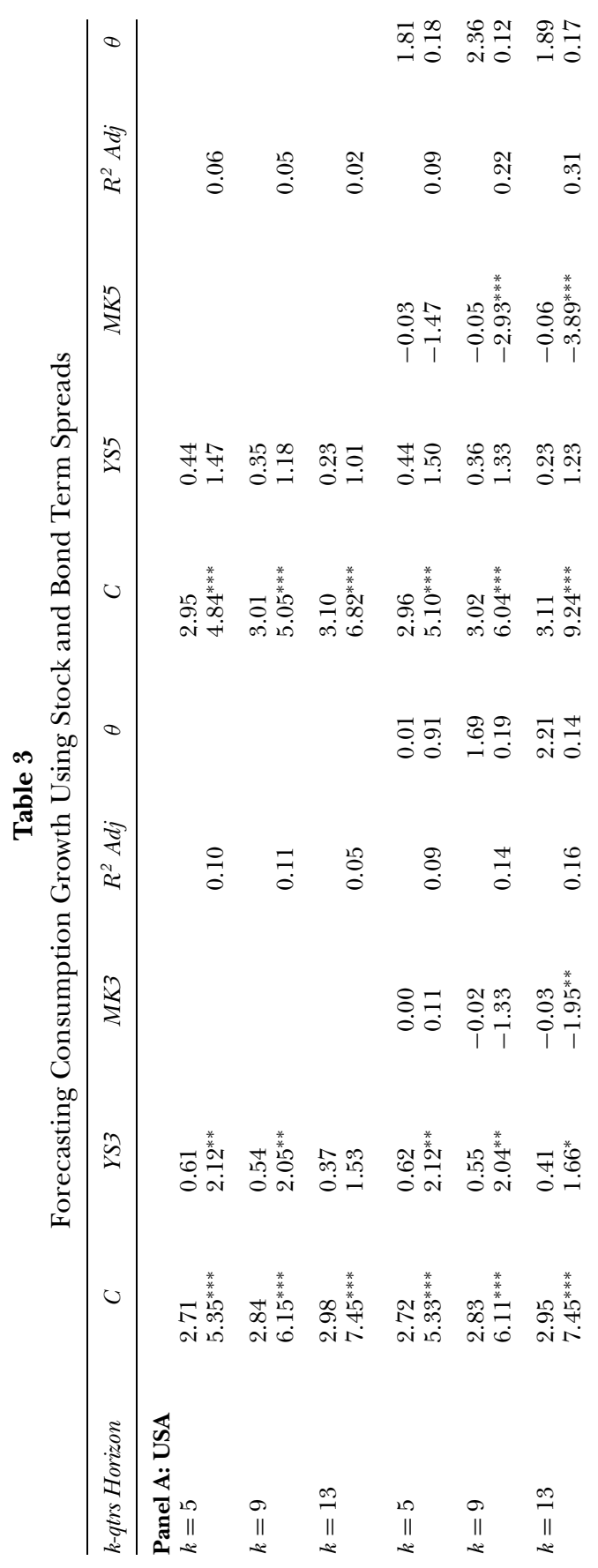




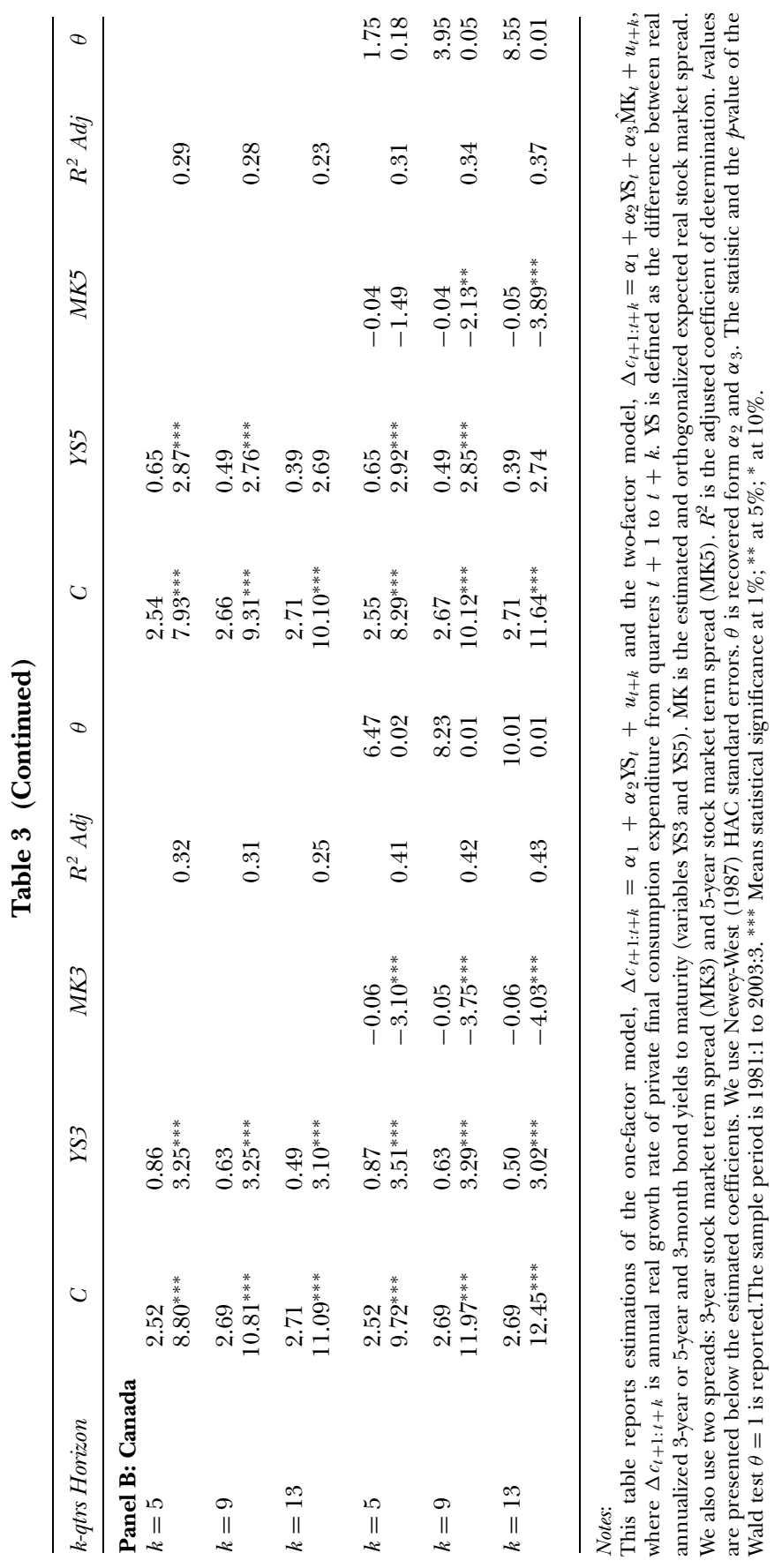


Table 4

Correlations Between the Regressors and the Proxy of Economic Growth

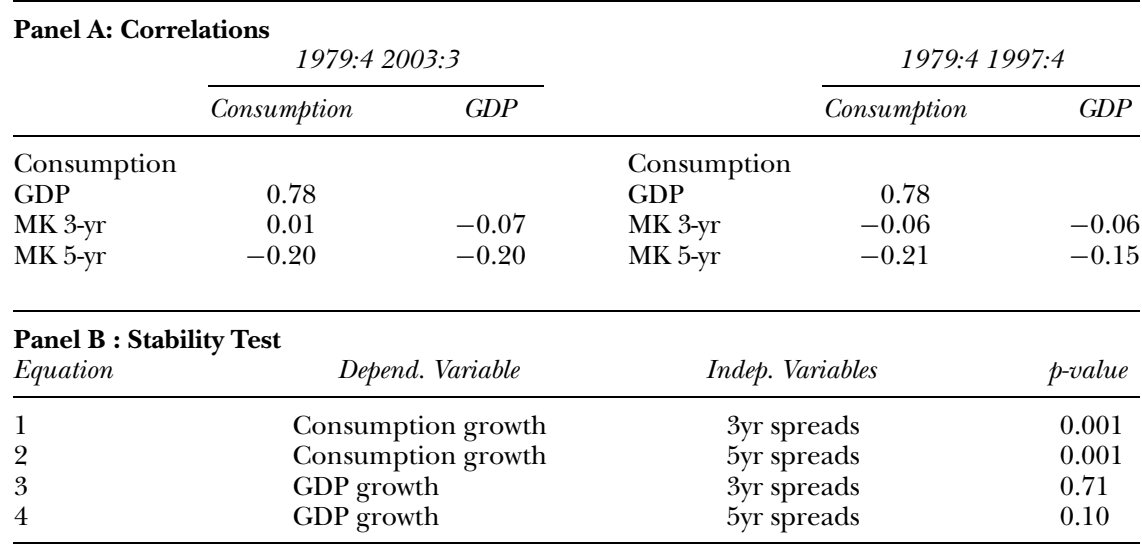

Notes:

Panel A shows contemporaneous correlations between real GDP growth and consumption growth, with estimated stock market term spreads (3-year and 5-year) MK. Spreads are lagged five periods to match equation (5) with $k=5$. Panel B reports the $p$-values of a stability test for the four equations, US data two-factor model. The break point tested is 1998:1. We use Andrews (2003) end-of-sample stability test.

between consumption growth and 3-year stock market term spread are positive in the full sample but negative when the bubble period is eliminated from the sample.

This information found at the end of the US sample, may generate instability in the model's parameters. In order to test our equations for possible structural change beginning in the first quarter of 1998, we use the end-of-sample stability test developed by Andrews (2003), generalizing the well known Chow (1960) test. The $p$-values are presented in Panel B of Table 4. The null hypothesis is that slope coefficients are the same over the full sample (1979:4 to 2003:3). An alternative hypothesis is that coefficients change after 1998:1. The hypothesis of stability is rejected at conventional significance levels when we use consumption, but not when we use GDP. Results are consistent with Fair (2003), who finds evidence of structural change in the US stock market data in the late 1990s.

Given this evidence of structural change after 1997, we fit the two-factor models into the sub-sample 1981:1 to 1997:4 (see Table 5). We can observe that the interest rate spread is significant in 23 out of 24 cases studied. ${ }^{16}$ Again stock market term spread is always negative. For Canada this new variable is significant in 11 cases out of 12 at the $5 \%$ levels, with both consumption growth and output growth. For the US data, stock market term spread is significant in 8 cases out of 12 .

We performed an additional robustness check test with US expected returns computed using a different stock market index. We use S\&P 500 index data and its

16 Dotsey (1998) supports the view that yield spread is generally a useful variable in predicting future growth in real GDP, but also indicates that it has become less useful in recent years. 


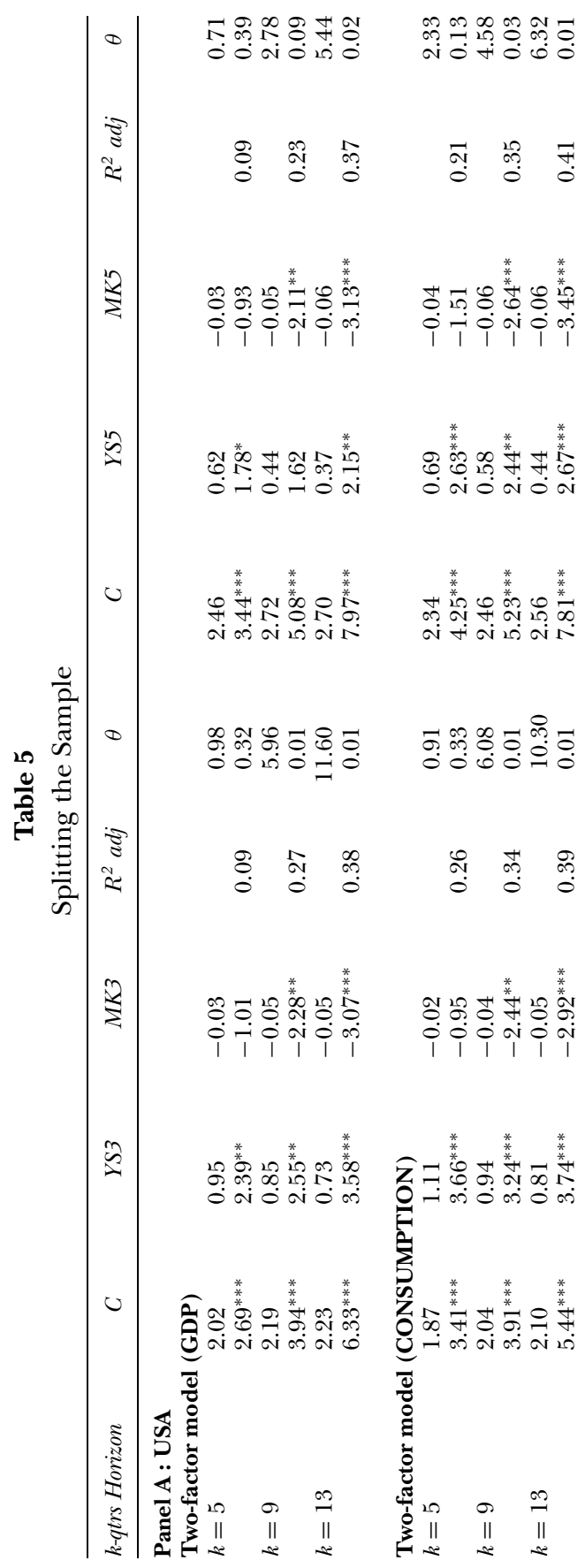




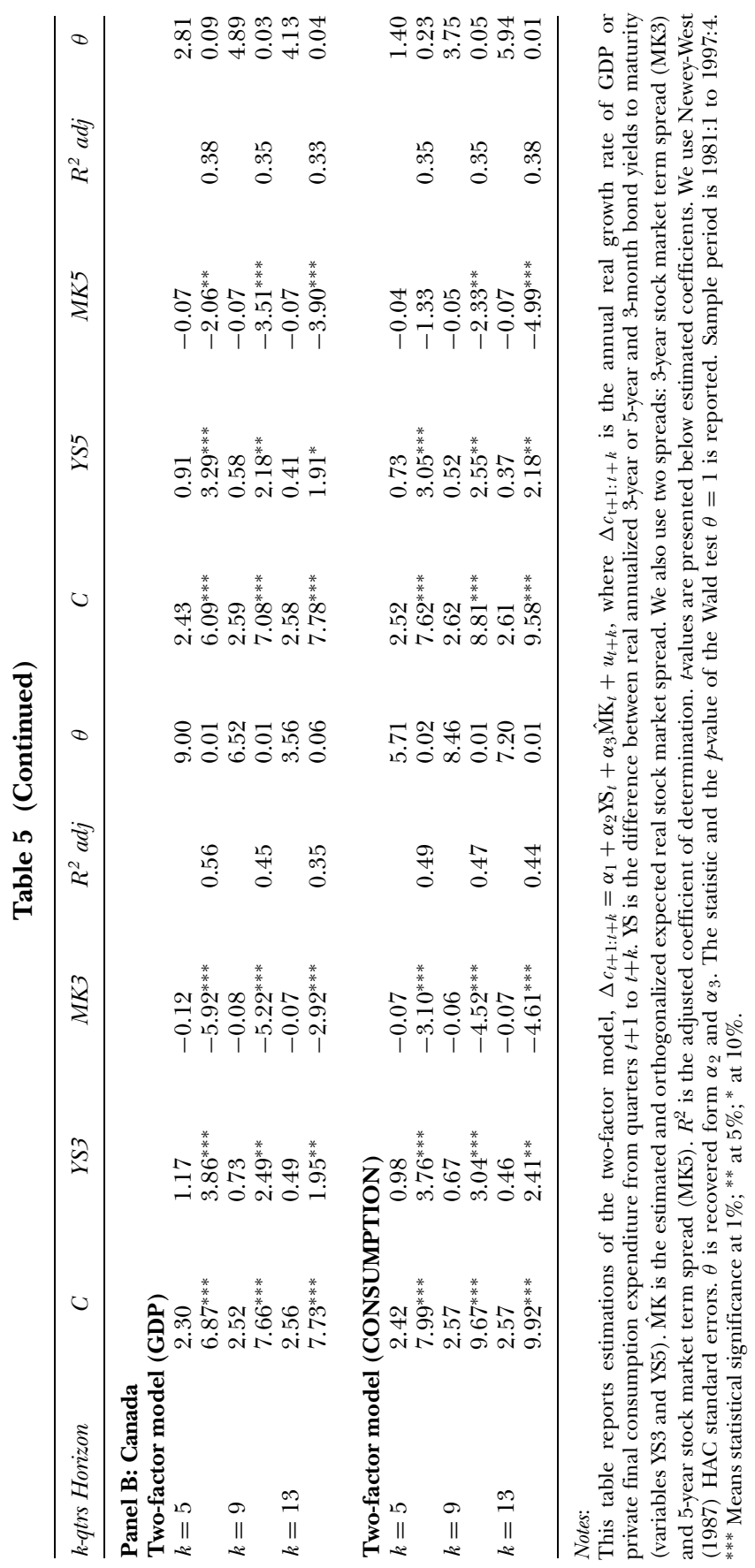


dividend yield. Both index and dividends data are obtained from Robert Shiller's website. Results are almost identical with respect to the MSCI index and are available on request from the authors.

To study the effect of the generating mechanism of a different expected return on the robustness of results, we compute expected stock market returns as the historical average measured at each date (equivalent to a regression of stock returns on a constant). We also impose non-negativity restrictions as before. Using the total sample, the stock market term spread coefficient is not significant for the US data. The Canadian stock market term spread coefficient was negative and significant 2 times out of 6 with GDP and 3 times out of 6 with consumption. Thus, it seems that the historical average stock returns generated poor forecasts of expected stock returns for both markets. Computing expected returns through historical means is not a particularly useful choice. Using information in fundamental variables may increase accuracy. ${ }^{17}$

We have documented the significance of interest rate term spreads as leading indicators of economic growth through the one-factor model. For the total sample period, the interest rate term spread provides valuable predictive information about future economic growth both for Canadian and US economies. The sign is always positive. Thus, a positive interest rate term spread is consistent with a subsequent increase in economic activity, whereas a negative interest rate term spread is consistent with a subsequent recession. Concerning the stock market term spread, empirical results are different. Its statistical relevance depends on the sample period. It is relevant for the Canadian economy in total sample, where its sign is negative. For the US data, the possible impact of the technology bubble and its aftermath affects results to some extent, but the sign is also negative. Thus, a positive market term spread is consistent with a subsequent recession, whereas a negative market term spread is consistent with a subsequent increase in economic activity. As mentioned in Section 2, a positive in yield spread and a negative in market term spread is consistent with an economy in which the inverse of the elasticity of substitution is larger than the relative risk aversion coefficient, and both are larger than one.

\section{CONCLUSIONS}

An important task of financial economics is to link the behaviour of asset prices to the real economy. In this paper we present a model based on consumption-based assetpricing framework with GIP preferences. From the Epstein-Zin-Weil Euler equation, and assuming that aggregate consumption and asset returns are jointly lognormal, a linear equation is derived providing an economic link among interest rate term spreads, expected stock market terms spreads and economic growth.

Empirical results suggest that interest rate term spreads and expected stock market term spreads are statistically significant factors in explaining real activity in Canada, and, to some extent, in the USA in the pre-technology bubble period. In these cases, explanatory power of the two-factor model for Canada and the USA is higher than the one factor (interest rate only) model.

Overall results suggest that, for Canada, in the time span studied (1979-2003), there is some relevant information about future output growth in the expected term structure

17 Results are available upon request from the authors. 
of the stock market, besides the well-known effects of interest rates. Results for the USA are less clear-cut, due to a possible structural break in stock market data. Results are robust to changes in measures of economic growth, stock prices, interest rates and expectation generating mechanisms.

This study also serves to document a potentially important link between financial variables and economic growth. All the above-mentioned facts have, as far as we know, been documented in this paper for the first time, in the framework of the CCAPM model with GIP preferences. These results clearly deserve further research. In particular, it would be fruitful to contrast our findings with data from other economies.

\section{REFERENCES}

Andrews, D. W. K. (2003), 'End-of-Sample Instability Tests', Econometrica, Vol. 71, No. 6, pp. 1661-94.

Beaudry, P. and E. van Wincoop (1995), 'The Intertemporal Elasticity of Substitution: An Exploration Using US Panel of State Data', Economica, Vol. 63, pp. 495-512.

Belsley, D. A., E. Kuh and R. E. Welsch (1980), Regression Diagnostics (John Wiley and Sons, New York, NY).

Bodman, P. M. and M. Crosby (2000), 'Phases of the Canadian Business Cycle', The Canadian Journal of Economics, Vol. 33, No. 3, pp. 618-33.

Breeden, D. T. (1979), 'An Intertemporal Asset Pricing Model with Stochastic Consumption and Investment Opportunities', Journal of Financial Economics, Vol. 7, No. 3, pp. 265-96.

Brunnermeier, M. and S. Nagel (2004), 'Hedge Funds and the Technology Bubble', The Journal of Finance, Vol. 59, No. 5, pp. 2013-40.

Butler, A. W., G. Gryllon and J. P. Weston (2004), 'Can Managers Forecast Aggregate Market Returns?', Unpublished Paper (University of South Florida and Rice University).

Campbell, J. Y. (1987), 'Stock Returns and the Term Structure', Journal of Financial Economics, Vol. 18, No. 2, pp. 373-400.

and N. G. Mankiw (1989), 'Consumption, Income, and Interest Rates: Reinterpreting the Time Series Evidence', in O. Blanchard and S. Fischer (eds.), NBER Macroeconomic Annual (MIT, Cambridge MA), pp. 185-216.

- and R. J. Shiller (1988), 'The Dividend-Price Ratio and Expectations of Future Dividends and Discount Factors', Review of Financial Studies, Vol. 1, No. 3, pp. 195228.

and S. Thompson (2005), 'Predicting the Equity Premium Out of Sample: Can Anything Beat the Historical Average?', Working Paper (Harvard Institute of Economic Research).

- M. Lettau, B. G. Malkiel and Y. Xu (2001), 'Have Individual Stocks Become More Volatile? An Empirical Exploration of Idiosyncratic Risk', The Journal of Finance, Vol. 56, pp. $1-45$.

Chow, G. C. (1960), 'Tests of Equality Between Sets of Coefficients in Two Linear Regressions', Econometrica, Vol. 28, pp. 591-605.

Cochrane, J. H.(1992), 'Explaining The Variance of Price-Dividend Ratios', Review of Financial Studies, Vol. 5, No. 2, pp. 243-80.

Constantinides, G. M., J. B. Donaldson and R. Mehra (2002), 'Junior Can't Borrow: A New Perspective on the Equity Premium Puzzle', Quarterly Journal of Economics, Vol. 117, pp. 269-96.

Derrig, R. A. and E. Orr (2004), 'Equity Risk Premium: Expectations Great and Small', North American Actuarial Journal, Vol. 8, No.1 (January), pp. 45-69.

Dotsey, M. (1998), 'The Predictive Content of the Interest Rate Term Spread for Future Economic Growth', FRB Richmond - Economic Review, Vol. 84, No. 3(Summer), pp. 31-51.

Epstein, L. G. and S. E. Zin (1989), 'Substitution, Risk Aversion, and the Temporal Behaviour of Consumption and Asset Returns: A Theoretical Framework', Econometrica, Vol. 57, No. 4, pp. 937-70. 
Epstein, L. G. and S. E. Zin (1991), 'Substitution, Risk Aversion, and the Temporal Behaviour of Consumption and Asset Returns: An Empirical Analysis', Journal of Political Economy, Vol. 99, No. 2, pp. 263-86.

Estrella, A. and G. A. Hardouvelis (1991), 'The Term Structure as a Predictor of Real Economic Activity', Journal of Finance, Vol. 46, No. 2, pp. 555-76.

Fair, R. C. (2004), 'Testing for a New Economy in the 1990's', Business Economics, Vol. 15, No. 2, pp. 283-97.

Fama, E. F. and K. R. French (1988a), 'Dividend Yields and Expected Stock Returns', Journal of Financial Economics, Vol. 22, No. 1, pp. 3-26.

(1988b), 'Permanent and Temporary Components of Stock Prices', Journal of Political Economy, Vol. 96, No. 2, pp. 246-73.

- (1989), 'Business Conditions and Expected Returns on Stocks and Bonds', Journal of Financial Economics, Vol. 25, No. 1, pp. 23-50.

Ferreira, E., M. Martínez, E. Navarro and G. Rubio (2003), 'Real Activity and Yield Spreads Under the Consumption-Based Asset Pricing Model', XI Foro de Finanzas (Universidad de Alicante, http://xiforofinanzas.ua.es/trabajos/1064.pdf).

Goyal, A. and I. Welch (2004), 'A Comprehensive Look at the Empirical Performance of Equity Premium Prediction', NBER Working Paper 10483.

Grossman, S. J. and R. J. Shiller (1981), 'The Determinants of the Variability of Stock Market Prices,' American Economic Review, Vol. 71, No. 2, pp. 222-27.

Hall, R. E. (1988), 'Intertemporal Substitution in Consumption', Journal of Political Economy, Vol. 96, No. 2, pp. 339-57.

Hamilton, J. D. and D. H. Kim (2002), 'A Re-examination of the Predictability of Economic Activity Using the Yield Spread', Journal of Money Credit and Banking, Vol. 34, No. 2, pp. 340-60.

Hansen, L. P. and K. J. Singleton (1982), 'Generalized Instrumental Variables Estimation of Nonlinear Rational Expectations Models', Econometrica, Vol. 50, No. 5, pp. 1269-86.

Harvey, C. R. (1988), 'The Real Term Structure and Consumption Growth', Journal of Financial Economics, Vol. 22, No. 2, pp. 305-34.

- (1989), 'Forecasts of Economic Growth from the Bond and Stock Markets', Financial Analyst Journal, Vol. 45, No. 5, pp. 38-45.

(1997), 'The Relation Between the Term Structure of Interest Rates and Canadian Economic Growth', Canadian Journal of Economics, Vol. 30, No. 1(February), pp. 169-93.

Haubrich, J. G. and A. M. Dombrosky (1996), 'Predicting Real Growth Using the Yield Curve', FRB Cleveland-Economic Review, Vol. 32, No. 1(1st-Qtr), pp.26-35.

Hodrick, R. J. (1992), 'Dividend Yields and Expected Stock Returns: Alternative Procedures for Influence and Measurement', Review of Financial Studies, Vol. 5, No. 3, pp. 357-86.

Jeager, A. (1991), 'The Slope of the Yield Curve as Predictor of Business Cycle Fluctuations', Working Paper 46 (WIFO, Vienna).

Kandel, S. and R. F. Stambaugh (1991), 'Asset Returns and Intertemporal Preferences', Journal of Monetary Economics, Vol. 27, pp. 39-71.

Keim, D. B. and R. F. Stambaugh (1986), 'Predicting Returns in the Stock and Bond Markets', Journal of Financial Economics, Vol. 17, No. 2, pp. 357-90.

Lettau, M. and S. Ludvigson (2001), 'Consumption, Aggregate Wealth and Expected Stock Returns', Journal of Finance, Vol. 56, pp. 815-49.

Lewellen, J. (2004), 'Predicting Returns with Financial Ratios', Journal of Financial Economics, Vol. 74, pp. 209-35.

Litterman, R. (1986), 'Forecasting with Bayesian Vector Autoregressions: Five Years of Experience', Journal of Business and Economic Statistics,Vol. 4, pp. 25-38.

Lucas, R. E., Jr. (1978), 'Asset Prices in an Exchange Economy', Econometrica, Vol. 46, No. 6, pp. 1429-46.

Mehra, R. and E. C. Prescott (1985), 'The Equity Premium: A Puzzle', Journal of Monetary Economics, Vol. 15, No. 2, pp. 145-62.

(2003), 'The Equity Premium in Retrospect', in G. Constantinides, M. Harris and R. Stulz (eds.), Handbook of the Economics of Finance (Amsterdam, Netherlands: NorthHolland). 
Menzly, L., T. Santos and P. Veronesi (2004), 'Understading Predictability', Journal of Political Economy (February), pp. 1-47.

Newey, W. K. and K. D. West (1987), 'A Simple, Positive Semi-Definite, Heteroskedasticity and Autocorrelation Consistent Covariance Matrix', Econometrica, Vol. 55, No. 3, pp. 703-8.

Obstfeld, M. (1994), 'Risk-taking, Global Diversification, and Growth', American Economic Review, Vol. 84, pp. 1310-29.

Plosser, C. I. and K. G. Rouwenhorst (1994), 'International Term Structures and Real Economic Growth', Journal of Monetary Economics, Vol. 33, No. 1, pp. 133-55.

Poterba, J. M. and L. H. Summers (1988), 'Mean Reversion in Stock Prices: Evidence and Implications', Journal of Financial Economics, Vol. 22, No. 1, pp. 27-60.

Restoy, F. and R. Rodríguez (2006), 'Can Fundamentals Explain Cross-country Correlations of Asset Returns', Review of World Economics, Vol. 142, No. 3.

Rodríguez, R., F. Restoy and J. I. Peña (2002), 'Can Output Explain the Predictability and Volatility of Stock Returns?', Journal of International Money and Finance, Vol. 21, pp. 16382.

Rubinstein, M. (1976), 'The Valuation of Uncertain Income Streams and the Pricing of Options', Bell Journal of Economics, Vol. 7, No. 2, pp. 407-25.

Stock, J. and M. Watson (1989), 'A New Index of Coincident and Leading Indicators', NBER, pp. 351-94.

Weil, P. (1990), 'Nonexpected Utility in Macroeconomics', Quarterly Journal of Economics, Vol. 105, No. 1, pp. 29-42.

Wooldridge, J. M. (2002), Econometric Analysis of Cross Section and Panel Data (The MIT Press, Cambridge). 